\title{
Drenagem interna como fator de diferenciação de Latossolos do Distrito Federal
}

\author{
Patrícia Maurício Campos(1), Marilusa Pinto Coelho Lacerda( ${ }^{(1)}$, Cícero Lopes da Silva ${ }^{(1)}$, \\ Marcos Aurélio Carolino de Sá(2) e Djalma Martinhão Gomes de Sousa(2)
}

\begin{abstract}
(1)Universidade de Brasília, Faculdade de Agronomia e Medicina Veterinária, Caixa Postal 40580, CEP 70.910-970 Brasília, DF. E-mail: patymauricio@gmail.com, marilusa@unb.br, cicero@unb.br (2)Embrapa Cerrados, Caixa Postal 08223, CEP 73.301-970 Planaltina, DF. E-mail: carolino@cpac.embrapa.br, dmgsousa@cpac.embrapa.br
\end{abstract}

Resumo - O objetivo deste trabalho foi determinar a influência de características físico-hídricas dos solos em atributos diagnóstico de Latossolos. Realizou-se o levantamento de atributos morfológicos, químicos, físicos, mineralógicos e físico-hídricos de cinco perfis de Latossolos Vermelhos (LV) e cinco perfis de Latossolos Vermelho-Amarelos (LVA) petroplínticos, considerados representativos dessa classe de solos no Distrito Federal. Além da caracterização dos atributos diagnóstico, a oscilação do nível freático dos solos foi monitorada por meio de poços de observação de 2,5 m de profundidade, durante um ano. Os Latossolos estudados foram considerados semelhantes química e fisicamente. Contudo, diferiram quanto às caracterizações morfológica e mineralógica, com a presença de horizontes concrecionários e goethita nos LVA. A estabilidade da goethita nesses solos foi influenciada pela oscilação do lençol freático. Constatou-se menor condutividade hidráulica saturada e menor variação da profundidade freática nos LVA, em razão da deficiência de drenagem interna causada pela presença dos horizontes concrecionários. Os LVA apresentam, portanto, menor potencial agrícola que os LV, no Distrito Federal. As características físico-hídricas de Latossolos têm pouca influência sobre atributos diagnóstico, com exceção da mineralogia dos óxidos de ferro, que apresentam os teores de goethita aumentados em condições de baixa drenagem interna.

Termos para indexação: concreções ferruginosas, condutividade hidráulica saturada, plintita, profundidade freática, regime hídrico.

\section{The internal drainage as a differentiation factor in Oxisols of Distrito Federal, Brazil}

\begin{abstract}
The objective of this work was to determine the influence of soil physicohydric characteristics on Oxisols diagnostic attributes. Morphological, chemical, physical, mineralogical and physicohydric attributes were surveyed in profiles of five Latossolos Vermelhos (Rhodic Haplustox, LV) and of five Latosssolos Vermelho-Amarelos (Typic Haplustox, LVA), considered representative of this kind of Oxisols in Distrito Federal, Brazil. Besides the soil diagnostic attributes characterization, the water-table oscillation was monitored using 2.5-m depth observation wells, during one year. The studied Oxisols were considered chemically and physically similar. However, they differed as to morphological and mineralogical characterization, with the presence of concretionary horizons and goethite in the LVA. Goethite stability in this soils was influenced by the water-table oscillation. The presence of concretionry horizons in LVA caused an internal drainage deficiency, which resulted in lower saturated hydraulic conductivity and lower variation of the water-table levels. Therefore, LVA soils show lower agricultural potential than LV ones, in Distrito Federal. Oxisols physicohydric characteristics have little influence on soil diagnostic attributes, except for iron oxides mineralogy, which show increased contents of goethite in low internal drainage conditions.
\end{abstract}

Index terms: iron concretions, saturated hydraulic conductivity, plinthite, groundwater depth, water regime.

\section{Introdução}

No Distrito Federal, os Latossolos Vermelhos (LV) destacam-se, com representatividade de $38,65 \%$ dos solos da região, enquanto os Latossolos Vermelho-Amarelos (LVA) representam $15,83 \%$
(Motta et al., 2002). O relevo da região é caracterizado por chapadas, onde normalmente os LV ocorrem nas áreas centrais e os LVA desenvolvem-se nas bordas dos topos. A vegetação nativa, comumente associada aos LV, varia de cerrado a cerradão, enquanto a que se

Pesq. agropec. bras., Brasília, v.45, n.3, p.306-314, mar. 2010 
desenvolve nos LVAs varia de cerrado strictu senso a campo cerrado (Haridasan, 2001).

Em estudos de associação da cobertura vegetal, com classes de solo no Bioma Cerrado, muita atenção tem sido dada à toxidez por alumínio e à fertilidade do solo (Ferreira et al., 2007), tendo sido menos estudados atributos como constituição mineralógica, disponibilidade hídrica e textura do solo. No entanto, os dois últimos atributos podem ser essenciais para o entendimento da ocorrência de determinada vegetação, independentemente dos fatores climáticos. Segundo Rossi et al. (2005), a capacidade de retenção de água dos solos deve merecer grande destaque como fator determinante da vegetação.

Os LV e LVA que ocorrem no Distrito Federal, em geral, são muito semelhantes entre si (Santos et al., 2006) e, normalmente, são provenientes de ardósias do grupo Paranoá. As principais diferenças entre esses solos são observadas em sua cor e pelo desenvolvimento de horizontes concrecionários a litoplínticos, nos LVA. A cor é determinada pela variação mineralógica dos óxidos de ferro e é condicionada pela predominância de goethita nos LVA e hematita nos LV (Gomes et al., 2004b). A formação da goethita pode ser consequência de baixos conteúdos de $\mathrm{Fe}_{2} \mathrm{O}_{3}$ nos materiais de origem ou atribuída à maior umidade ou deficiência de drenagem interna nos perfis de LVA, decorrentes da presença de horizontes concrecionários a litoplínticos (Gomes et al., 2004a, 2004b).

Propriedades hidráulicas dos solos têm sido estudadas intensamente nos últimos anos, entretanto, a relação com as propriedades morfológicas dos solos ainda não foi bem estabelecida (Marques et al., 2002).

O objetivo deste trabalho foi determinar a influência de características físico-hídricas dos solos em atributos diagnóstico de Latossolos do Distrito Federal.

\section{Material e Métodos}

A Fazenda Água Limpa da Universidade de Brasília (FAL-UnB) foi utilizada como área-piloto para este trabalho, por apresentar distribuição de Latossolos Vermelhos e Vermelho-Amarelos petroplínticos sob vegetação nativa diversificada, em ambiente composto pelas duas principais superfícies geomorfológicas do Distrito Federal, a primeira com altitudes entre 1.100 e $1.300 \mathrm{~m}$ e a segunda entre 1.000 e $1.100 \mathrm{~m}$, conforme Motta et al. (2002). O substrato geológico é representado pela unidade ardósias do grupo Paranoá.

A FAL-UnB localiza-se na porção centro-oeste do Distrito Federal, entre as coordenadas geográficas $15^{\circ} 31^{\prime} \mathrm{S}$ e $16^{\circ} 03^{\prime} \mathrm{S}$ e $47^{\circ} 42^{\prime} \mathrm{W}$ e $48^{\circ} 14^{\prime} \mathrm{W}$. O clima predominante da região, segundo Köppen, é o tropical de savana, com a concentração da precipitação pluviométrica no verão.

Foram selecionados, georreferenciados e avaliados, aos pares, cinco perfis de Latossolos Vermelho-Amarelos (LVA), com ocorrência de horizontes concrecionários a litoplínticos, e cinco perfis de Latossolos Vermelhos (LV). Os pares de solo (LVA e LV) estavam distribuídos em condições semelhantes de paisagem (altitude, relevo e posição na superfície geomorfológica), o que serviu como garantia para que os solos de um mesmo par tivessem influência de fatores de formação semelhantes. A localização dos perfis estudados foi determinada de acordo com o posicionamento dos solos nas superfícies geomorfológicas, segundo Motta et al. (2002).

A descrição morfológica dos perfis foi realizada em trincheiras conforme Santos et al. (2005). A amostragem para a realização das análises laboratoriais foi realizada nos horizontes $\mathrm{A}$ e $\mathrm{Bw}$, dos quais foram obtidas amostras deformadas e indeformadas, com três repetições.

O acompanhamento da variação da profundidade freática foi realizado por meio de poços de observação, abertos até a profundidade de $250 \mathrm{~cm}$, localizados próximos a cada trincheira. O monitoramento da oscilação freática dentro do poço foi feito com boia e contrapeso de chumbo. As medições foram feitas semanalmente, ao longo do ano agrícola 2007/2008, e os resultados das variações freáticas foram expressos em termos de profundidade da superfície do terreno ao nível freático. O registro da precipitação acumulada foi obtido da estação climatológica da FAL-UnB, no período coincidente com a observação da variação do lençol freático.

Para as análises físico-hídricas e as de agregados, foram utilizadas cinco repetições: uma amostra por trincheira, das cinco utilizadas para cada classe de 
solo (LVA ou LV). Para as análises mineralógicas, as amostras foram quarteadas até que atingissem boa representatividade.

As análises químicas do complexo sortivo e as de ataque da fração argila com ácido sulfúrico foram realizadas conforme Claessen (1997).

A determinação da composição mineralógica foi realizada por difratometria de raios-X (DRX) com o difratômetro Rigaku, modelo Geiger Fix D-Max-B, a partir da fração argila dos horizontes $\mathrm{Bw}$ dos Latossolos, em que as lâminas, confeccionadas pelo método do esfregaço, foram submetidas aos seguintes tratamentos (Claessen, 1997): argila normal, sem aquecimento; argila submetida à concentração de óxidos de ferro; e argila aquecida a $500^{\circ} \mathrm{C}$; no total de 30 lâminas, correspondentes às 10 trincheiras em estudo.

A caracterização física foi realizada pela análise granulométrica, conforme o método de Boyoucos, e pela determinação da densidade e da porosidade total do solo, obtida indiretamente pela relação entre a densidade do solo e a densidade de partículas, conforme Claessen (1997).

Para a caracterização dos agregados, obtiveram-se amostras com diâmetros entre 2 e $8 \mathrm{~mm}$, denominadas amostras 8-2 mm, que foram submetidas à avaliação da estabilidade de agregados no solo por via úmida, com o auxílio do aparelho de Yoder, com a individualização das seguintes classes de agregados: $>2 \mathrm{~mm}, 2-1 \mathrm{~mm}, 1-0,5 \mathrm{~mm}, 0,5-0,25 \mathrm{~mm}, 025-$ 0,106 mm, e $<0,106$ mm, segundo Kemper \& Chepil (1965).

A percentagem de agregados, em cada peneira, foi obtida pela divisão da massa de solo seco em cada peneira pela massa de matéria seca total das amostras, e posterior multiplicação por 100 .

O diâmetro médio ponderado (DMP 8-2 mm) foi calculado pela determinação das frequências de agregados em cada classe ( $\mathrm{Fi}, \%)$ e dos diâmetros médios em cada classe (Xi), obtido pela média entre as aberturas da peneira passada e da peneira retida, expresso em milímetro, de acordo com Youker \& McGuinness (1956), conforme a equação $\mathrm{DMP}=\sum(\mathrm{Fi} \mathrm{Xi}) / 100$, em que i variou de 1 a 5 .

Para a determinação da distribuição de agregados, as amostras de solo foram peneiradas apenas na peneira de $8 \mathrm{~mm}$, para obtenção de amostras constituídas por todos os agregados menores que
$8 \mathrm{~mm}$, denominadas amostras $<8 \mathrm{~mm}$, que foram submetidas à avaliação de distribuição de agregados em cada classe de diâmetro, conforme descrito anteriormente.

Para a caracterização físico-hídrica dos solos, em cada amostra indeformada dos horizontes A e $\mathrm{Bw}$ dos solos estudados, foram realizadas análises de condutividade hidráulica saturada (Claessen, 1997), posteriormente corrigidas para condutividade hidráulica saturada a $20^{\circ} \mathrm{C}$ [Ks (20)]. Além disso, foi determinada a curva de retenção de água (Freitas Júnior \& Silva, 1984).

Para a condutividade hidráulica saturada, foi adotado o intervalo de confiança obtido pelo teste $\mathrm{t}$, a $1 \%$ de probabilidade, para identificar o grau de semelhança desse atributo entre os Latossolos estudados.

Para evidenciar possíveis diferenças entre as curvas de retenção de água dos solos estudados, adotou-se o teste da razão de verossimilhança (Motulsky \& Christopulos, 2003), que consistiu em comparar a diferença entre as somas de quadrados residuais (SQR) das curvas de retenção elaboradas a partir de dois modelos: hipótese nula, em que não há diferença entre a retenção de água dos dois solos; e hipótese alternativa, em que há diferença. $\mathrm{O}$ ajuste da curva foi determinado segundo o modelo de Van Genutchen (1980), com o programa "Soil Water Retention Curve" (SWRC version 3 beta), para o cálculo da soma de quadrados das curvas obtidas (SQ) das hipóteses, nos horizontes A e B dos solos analisados.

\section{Resultados e Discussão}

Pela análise morfológica, observou-se que os Latossolos Vermelhos apresentaram perfil homogêneo profundo (superior a $1 \mathrm{~m}$ ) e sem impedimentos, enquanto os Latossolos Vermelho-Amarelos apresentaram horizonte concrecionário ou litoplíntico (F) de espessuras variáveis, geralmente desenvolvidos abaixo dos horizontes Bw (Tabela 1).

Além da cor, a cobertura vegetal nativa associada às duas classes de solo também diferiu. A vegetação nativa é um reflexo, entre outros fatores, do tipo de solo e, portanto, pode constituir um primeiro diagnóstico na análise de variabilidade entre solos (Haridasan, 2001). Os Latossolos Vermelhos 
associaram-se à vegetação cerrado strictu senso ou na profundidade estudada, não foi constatada cerradão (Tabela 1). A presença do lençol freático, durante o período de observação (Figura 1), o

Tabela 1. Características morfológicas e físicas dos perfis de Latossolos estudados no Distrito Federal ${ }^{(1)}$.

\begin{tabular}{|c|c|c|c|c|c|c|c|c|}
\hline Perfil & Horizonte & Profundidade & Cor & Textura & $\begin{array}{c}\text { Ds } \\
\left(\mathrm{g} \mathrm{cm}^{-3}\right)\end{array}$ & $\begin{array}{c}\mathrm{Pt} \\
\left(\mathrm{cm}^{3} \mathrm{~cm}^{-3}\right)\end{array}$ & $\begin{array}{c}\text { DMP 8-2 } \\
(\mathrm{mm})\end{array}$ & Vegetação \\
\hline & & & & LatossoloVermell & narelo ác & plíntico & & \\
\hline \multirow[t]{3}{*}{ I } & A & $0-35 \mathrm{~cm}$ & 5 YR 4/6 & Argilosa & 0,72 & 0,71 & 4,82 & Campo \\
\hline & $\mathrm{Bw}$ & $35-66 \mathrm{~cm}$ & $10 \mathrm{YR} 7 / 8$ & Muito argilosa & 0,94 & 0,63 & 4,01 & \\
\hline & $\mathrm{F}$ & $66-136 \mathrm{~cm}$ & - & - & - & - & - & \\
\hline \multirow[t]{3}{*}{ III } & A & $0-54 \mathrm{~cm}$ & 5 YR 4/6 & Argilosa & 0,74 & 0,69 & 4,58 & Campo cerrado \\
\hline & $\mathrm{Bw}$ & $54-135 \mathrm{~cm}$ & 10 YR $7 / 8$ & Argilosa & 0,85 & 0,66 & 4,50 & \\
\hline & $\mathrm{F}$ & $135-337 \mathrm{~cm}$ & - & - & - & - & - & \\
\hline \multirow[t]{3}{*}{ V } & A & $0-45 \mathrm{~cm}$ & 5 YR 4/6 & Argilosa & 0,85 & 0,66 & 4,53 & Campo cerrado \\
\hline & $\mathrm{Bw}$ & $45-70 \mathrm{~cm}$ & 7,5 YR 6/8 & Muito argilosa & 0,94 & 0,63 & 4,74 & \\
\hline & $\mathrm{F}$ & $70-134 \mathrm{~cm}$ & - & - & - & - & - & \\
\hline \multirow[t]{3}{*}{ VII } & A & $0-36 \mathrm{~cm}$ & 5 YR 4/6 & Argilosa & 0,85 & 0,66 & 4,83 & Campo cerrado \\
\hline & $\mathrm{Bw}$ & $36-75 \mathrm{~cm}$ & 7,5 YR 6/6 & Argilosa & 0,91 & 0,64 & 4,44 & \\
\hline & $\mathrm{F}$ & $75-112 \mathrm{~cm}$ & - & - & - & - & - & \\
\hline \multirow[t]{4}{*}{ IX } & A & $0-52 \mathrm{~cm}$ & 5 YR 4/6 & Muito argilosa & 0,80 & 0,68 & 4,85 & Campo cerrado \\
\hline & $\mathrm{Bw}$ & $52-142 \mathrm{~cm}$ & 7,5 YR $6 / 8$ & Muito argilosa & 0,87 & 0,66 & 3,94 & \\
\hline & $\mathrm{F}$ & $142-210 \mathrm{~cm}$ & - & - & - & - & - & \\
\hline & \multicolumn{8}{|c|}{ Latossolo Vermelho ácrico típico } \\
\hline \multirow[t]{2}{*}{ II } & A & $0-56 \mathrm{~cm}$ & $10 \mathrm{R} 2,5 / 2$ & Muito argilosa & 0,75 & 0,70 & 4,76 & Cerradão \\
\hline & Bw & $56 \mathrm{~cm}+$ & $10 \mathrm{R} 4 / 8$ & Muito argilosa & 0,83 & 0,67 & 4,63 & \\
\hline \multirow[t]{2}{*}{ IV } & A & $0-60 \mathrm{~cm}$ & 10 R 3/2 & Muito argilosa & 0,71 & 0,71 & 4,68 & Cerrado strictu \\
\hline & Bw & $60 \mathrm{~cm}+$ & $2,5 \mathrm{YR} 4 / 8$ & Muito argilosa & 0,78 & 0,69 & 4,47 & senso \\
\hline \multirow[t]{2}{*}{ VI } & A & $0-58 \mathrm{~cm}$ & 10 R $3 / 4$ & Muito argilosa & 0,69 & 0,73 & 4,58 & Cerrado strictu \\
\hline & Bw & $58 \mathrm{~cm}+$ & $10 \mathrm{R} 4 / 8$ & Muito argilosa & 0,81 & 0,68 & 4,11 & senso \\
\hline \multirow[t]{2}{*}{$\mathrm{VIII}^{(2)}$} & A & $0-40 \mathrm{~cm}$ & 10 R 3/6 & Muito argilosa & 0,82 & 0,66 & 4,66 & Cerrado strictu \\
\hline & $\mathrm{Bw}$ & $40 \mathrm{~cm}+$ & 2,5 YR 3/6 & Muito argilosa & 0,89 & 0,65 & 4,29 & senso \\
\hline \multirow[t]{2}{*}{$\mathrm{X}$} & A & $0-44 \mathrm{~cm}$ & 2,5 YR 3/6 & Muito argilosa & 0,69 & 0,73 & 4,76 & Cerradão \\
\hline & $\mathrm{Bw}$ & $44 \mathrm{~cm}+$ & 2,5 YR 4/8 & Muito argilosa & 0,78 & 0,70 & 4,65 & \\
\hline
\end{tabular}

${ }^{(1)} \mathrm{Ds}$, densidade do solo; Pt, porosidade total; DMP 8-2, diâmetro médio ponderado. ${ }^{(2)} \mathrm{O}$ horizonte $\mathrm{Bw}$ do perfil VIII não apresentou $\mathrm{pH}$ em $\mathrm{KCl}$ superior a 5 , contudo, o $\Delta \mathrm{pH}$ positivo supre a condição para o caráter ácrico desse solo.

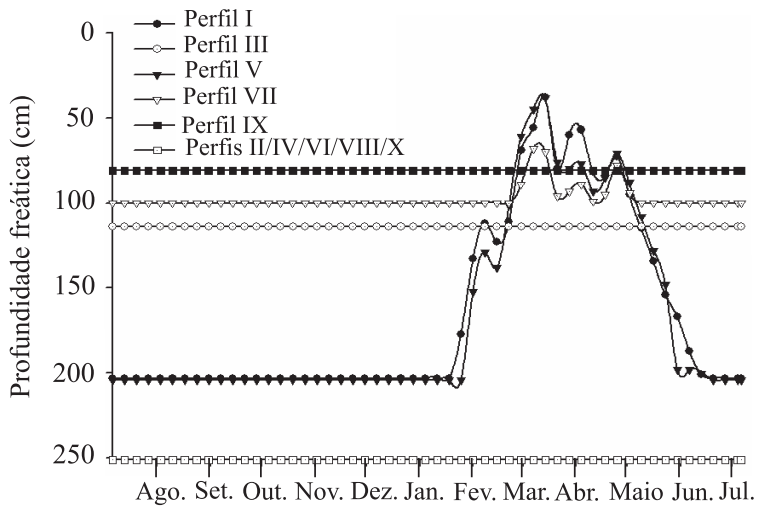

Meses

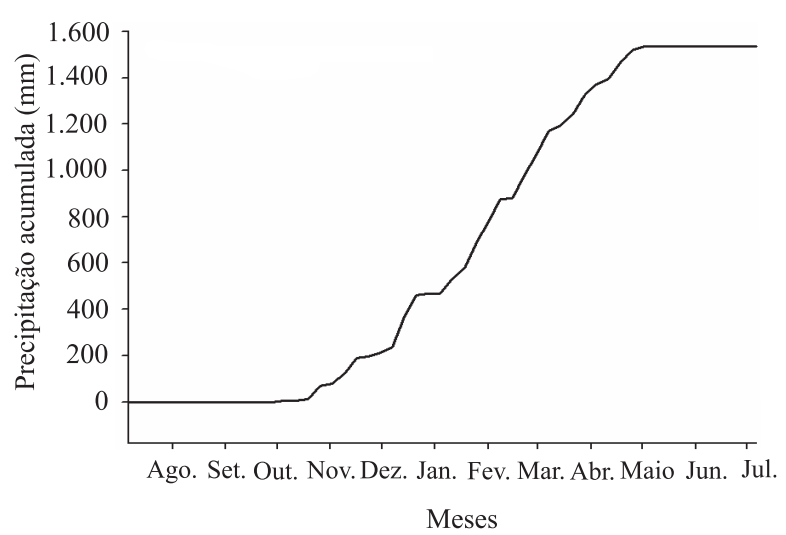

Figura 1. Oscilação da profundidade freática e precipitação acumulada, nos Latossolos estudados, no Distrito Federal, no ano agrícola de 2007/2008. 
que está de acordo com a presença da vegetação nesse solo. Nos Latossolos Vermelho-Amarelos petroplínticos, particularmente nos perfis I, V e VII, que apresentaram horizontes litoplínticos, a profundidade freática acompanhou os valores de precipitação acumulada. Os horizontes litoplínticos dos perfis I, V e VII apresentaram menor profundidade que os perfis III e IX, nos quais foram observadas oscilações do lençol freático somente abaixo dos horizontes $\mathrm{F}$ concrecionários. Além da menor profundidade dos horizontes litoplínticos nos perfis I, V e VII, a continuidade das petroplintitas, com pouca matriz terrosa, constitui notável impedimento à penetração das raízes e ao livre fluxo da água (Santos et al., 2006). Assim, esses solos foram associados a um tipo de vegetação mais rala, denominado campo cerrado.

Os solos estudados apresentaram características químicas semelhantes no horizonte A (Tabela 2), com valores de CTC e teores de matéria orgânica semelhantes, $\mathrm{pH}$ ácido e carência generalizada de nutrientes. Gomes et al. (2004a, 2004b) também observaram semelhança entre essas características, nessas duas classes de solo, na região do Distrito Federal. Apesar da semelhança química, podem-se observar quantidades ligeiramente superiores de matéria orgânica nos horizontes A dos Latossolos
Vermelho-Amarelos ácricos petroplínticos, o que é indício de um ambiente menos favorável à decomposição, uma vez que se pode esperar que o aporte de material orgânico nesses solos seja menor do que no LV, tendo-se em vista a cobertura vegetal dos dois solos. De acordo com Gomes et al. (2004a, $2004 b)$, a formação de hematita $\left(\mathrm{Fe}_{2} \mathrm{O}_{3}\right)$ ou goethita $(\mathrm{FeOOH})$ é condicionada, principalmente, por dois fatores: teor de $\mathrm{Fe}_{2} \mathrm{O}_{3}$ no material de origem, em que maiores teores favorecem solos com formação preferencial de hematita; e conformação do óxido de ferro nas diferentes condições ambientais (particularmente umidade), pois a hematita é estável em ambientes bem aerados e a goethita estável nos pouco aerados. Os teores de $\mathrm{Fe}_{2} \mathrm{O}_{3}$ foram semelhantes (Tabela 2) nos solos estudados e permitiram sua classificação como mesoférricos (Santos et al., 2006). Assim, pode-se dizer que a hipótese mais provável na atribuição da cor dos solos estudados está relacionada a condições ambientais e à diferença de drenagem natural nos perfis avaliados, em consequência da presença de horizontes concrecionários a litoplínticos nos Latossolos Vermelho-Amarelos, que teriam proporcionado ambientes redutores por maior período de tempo e com maior frequência. Nessas condições, o ferro adota a sua forma hidratada, ou seja, a goethita é prioritariamente formada, com

Tabela 2. Atributos químicos dos perfis de Latossolos estudados no Distrito Federal ${ }^{(1)}$.

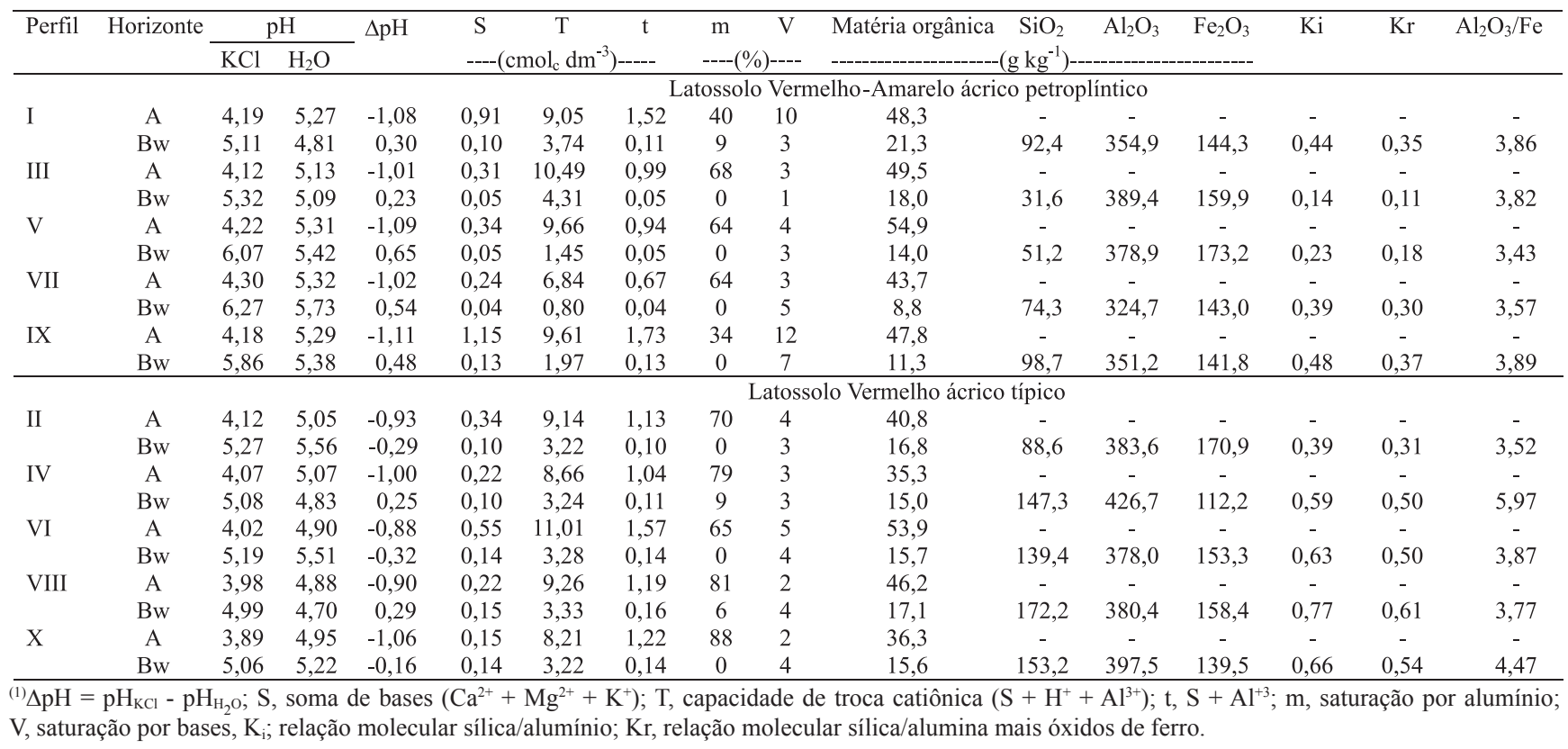


aparecimento da coloração amarelada, conforme constatado por Motta et al. (2002) e Gomes et al. (2004a, 2004b).

Ambos os Latossolos apresentaram hematita e goethita em seus horizontes Bw (Figura 2). Contudo, a proporção desses minerais em cada solo variou, com proporções de goethita mais elevadas nos perfis do LVA. A presença de horizontes concrecionários a litoplínticos nos LVA estudados interferiu na profundidade e oscilação do lençol freático nesses solos, com reflexos sobre a drenagem interna nos perfis, o que teria contribuído para a formação da goethita. Esse resultado poderia justificar a variação observada na cor dos solos, com a tonalidade amarelada resultante de maiores teores de goethita (Campos, 2001).

Com relação à análise de estabilidade dos agregados em água, os valores de diâmetro médio ponderado (DMP 8-2 $\mathrm{mm}$ ) dos horizontes Bw, os LVA apresentaram valores discretamente menores em relação aos dos LV (Tabela 1), o que é indício
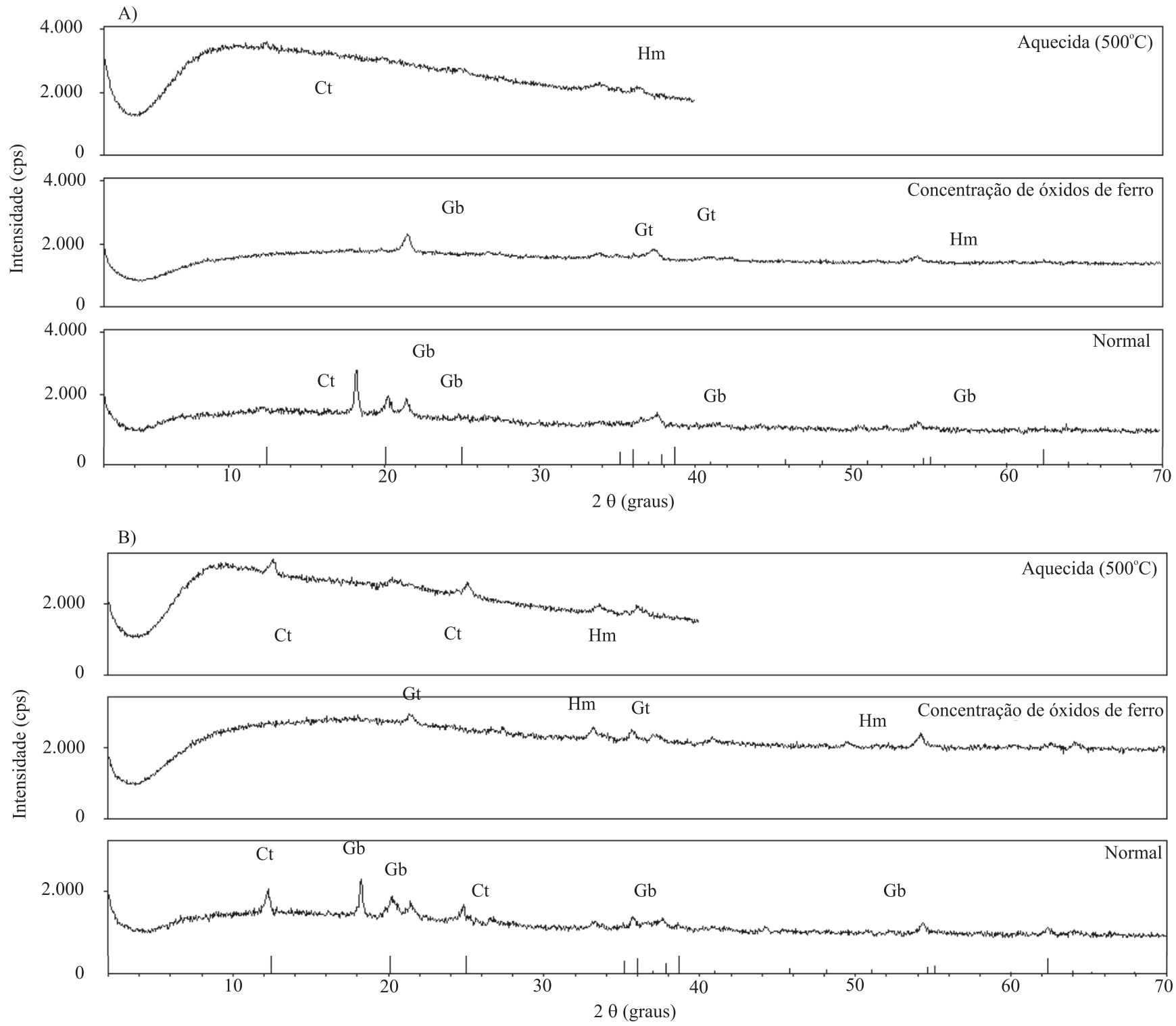

Figura 2. Difratogramas de raios-X do horizonte Bw dos perfis VII, Latossolo Vermelho-Amarelo (A), e VIII, Latossolo Vermelho (B), com os diferentes tratamentos da fração argila. Gb, gibbsita; Ct, caulinita; Hm, hematita; Gt, goethita. 
de menor estabilidade dos agregados no primeiro solo. Esse resultado pode ser explicado pela interferência dos horizontes concrecionários a litoplínticos na flutuação do lençol freático nos LVA, que poderia resultar em ciclos repetidos de umedecimento e secagem nos perfis, e poderia proporcionar o enfraquecimento e quebra de agregados. No entanto, os bons índices de agregação observados em ambos os solos estão em conformidade com os de solos ricos em sesquióxidos (Lima \& Anderson, 1997; Ferreira et al., 1999a, 1999b; Giarola et al., 2002; Pedrotti et al., 2003), inclusive com presença significativa de gibbsita. A maior estabilidade de agregados nos LV refletiu-se sobre a densidade aparente desses solos.

Nos LV, os agregados apresentaram distribuição regular ao longo dos diâmetros analisados, com predominância de agregados ao redor de $0,25 \mathrm{~mm}$ (Figura 3). Nos LVA, a distribuição dos agregados não foi uniforme em relação aos diâmetros avaliados. Esse resultado indica ambiente pedogenético mais equilibrado nos LV em relação aos LVA.

Os valores mais elevados de condutividade hidráulica saturada a $20^{\circ} \mathrm{C}$ foram observados nos horizontes A, de ambos os solos (1.163 $\mathrm{mm} \mathrm{h}^{-1}$, no LVA e $1.018 \mathrm{~mm} \mathrm{~h}^{-1}$ no LV), sem diferença significativa entre eles. Provavelmente, esse resultado deveu-se aos maiores teores de matéria orgânica e à maior porosidade total nesses horizontes (Tabelas 1 e 2). A matéria orgânica, por aumentar a agregação e por contribuir com a maior conectividade dos poros, favorece a percolação da água nos solos e condiciona maior condutividade hidráulica saturada. Em relação aos horizontes $\mathrm{Bw}$, os valores médios de Ks (20), obtidos nos LV (621 $\left.\mathrm{mm} \mathrm{h}^{-1}\right)$, foram maiores que os observados nos LVA $\left(127 \mathrm{~mm} \mathrm{~h}^{-1}\right)$. Como nos horizontes $\mathrm{Bw}$ os teores de matéria orgânica são substancialmente menores do que nos horizontes superficiais, os fatores determinantes para Ks (20) devem estar associados à porosidade total e à distribuição dos agregados (Figura 3B) nesses horizontes (Ferreira et al., 1999a, 1999b).

Os Latossolos estudados apresentaram curvas de retenção de umidade semelhantes, tanto nos horizontes A quanto nos Bw (Figura 4). Segundo Silva \& Azevedo (2001), um formato análogo dessas curvas indica que a natureza mineralógica e estrutural dos meios porosos desses solos é semelhante. As curvas expressam uma tendência típica dos Latossolos argilosos do Cerrado, com queda quase abrupta próximo à tensão $33 \mathrm{kPa}$, a partir de quando ela se torna assintótica ao eixo X. Os teores elevados de água em baixas tensões estão de acordo com os resultados de alta porosidade total e baixa densidade do solo observados no presente trabalho.
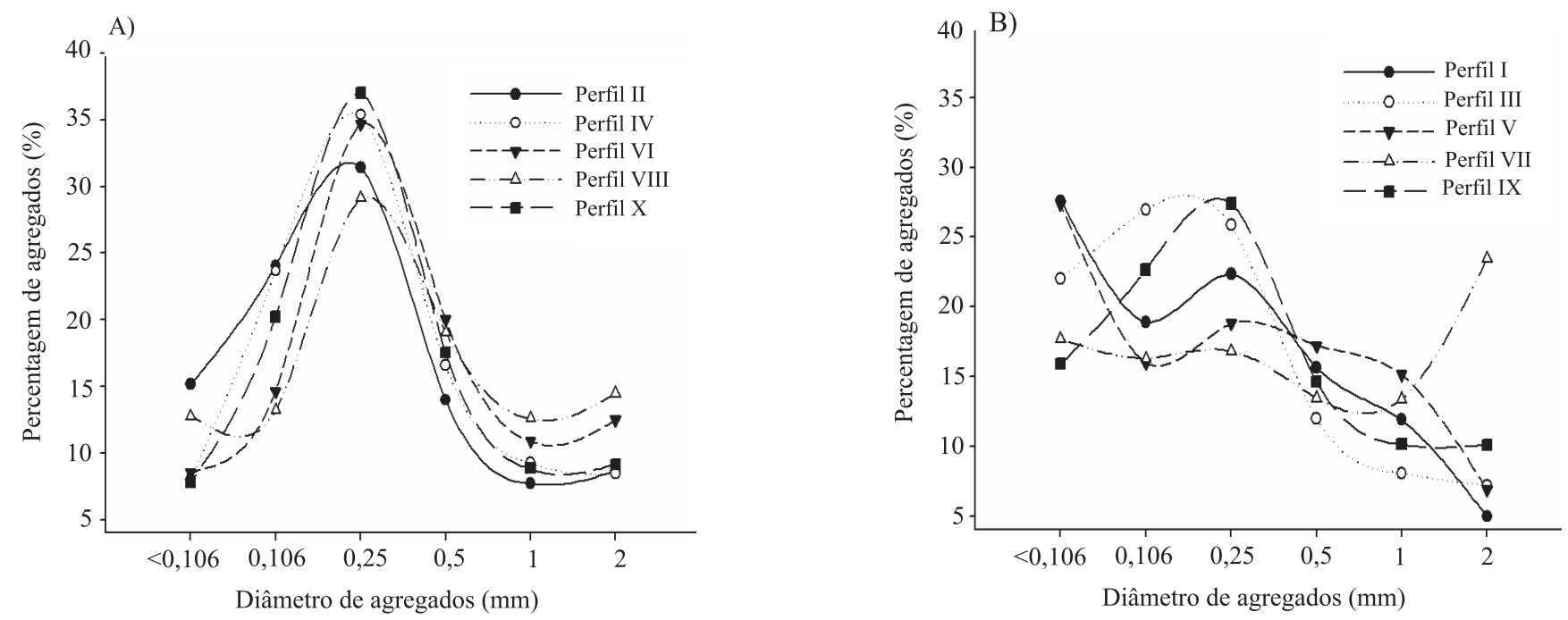

Figura 3. Distribuição de agregados menores do que $8 \mathrm{~mm}$ dos horizontes Bw, dos Latossolos Vermelhos (A) e Latossolos Vermelho-Amarelos (B) no Distrito Federal. 

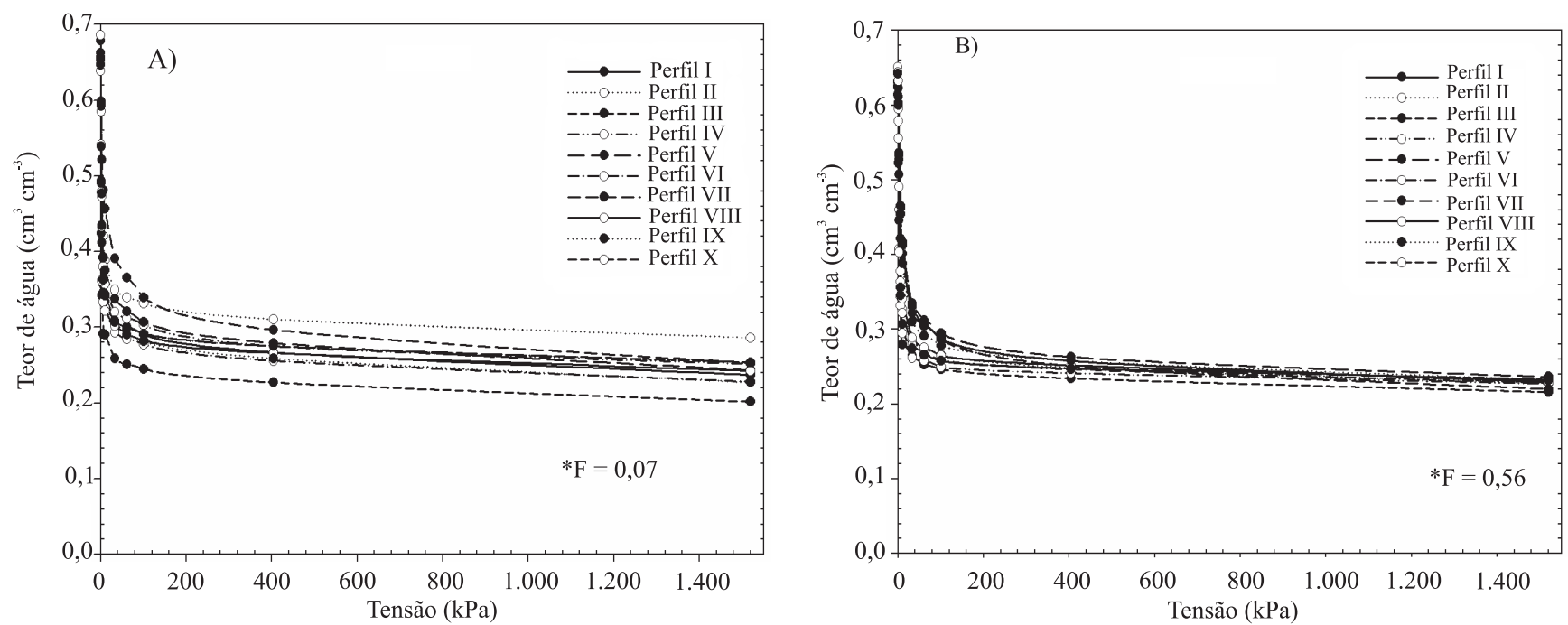

Figura 4. Curva característica de rentenção de água dos horizontes A (A) e Bw (B) dos Latossolos Vermelhos e VermelhoAmarelos no Distrito Federal, em que $\mathrm{F}>0,05$ significa curvas iguais pelo teste $\mathrm{F}$.

\section{Conclusões}

1. Os Latossolos estudados apresentam semelhanças químicas, físicas e mineralógicas, e os atributos diagnóstico que mais diferem entre eles são a cor e a presença de horizonte concrecionário.

2. A formação de horizonte concrecionário nos Latossolos Vermelho-Amarelos estudados está associada à ocorrência de menores condutividades hidráulicas e variações da profundidade freática, que resultam em menores drenagens internas.

3. A baixa drenagem interna do solo influencia a mineralogia dos óxidos de ferro, em razão do aumento na estabilidade da goethita nessas condições.

\section{Agradecimentos}

À Embrapa, pelo suporte às análises laboratoriais; a Wagner Campos, pelo apoio nas análises de campo.

\section{Referências}

CAMPOS, R.C. Determinação da cor do solo e sua utilização na predição dos teores de hematita. 2001. 59p. Dissertação (Mestrado) - Escola Superior de Agricultura Luiz de Queiroz, Piracicaba.

CLAESSEN, M.E.C. (Org.). Manual de métodos de análise de solo. 2.ed. rev. atual. Rio de Janeiro: Embrapa-CNPS, 1997. 212p.
FERREIRA, I.C. de M.; COELHO, R.M.; TORRES, R.B.; BERNACCI, L.C. Solo e vegetação nativa remanescente no Município de Campinas. Pesquisa Agropecuária Brasileira, v.42, p.1319-1327, 2007.

FERREIRA, M.M.; FERNANDES, B.; CURI, N. Influência da mineralogia da fração argila nas propriedades físicas de Latossolos da Região Sudeste do Brasil. Revista Brasileira de Ciência do Solo, v.23, p.515-524, 1999a.

FERREIRA, M.M.; FERNANDES, B.; CURI, N. Mineralogia da fração argila e estrutura de Latossolos da Região Sudeste do Brasil. Revista Brasileira de Ciência do Solo, v.23, p.507-514, 1999b.

FREITAS JÚNIOR, E.; SILVA, E.M. da. Uso de centrífuga para determinação da curva de retenção de água do solo, em uma única operação. Pesquisa Agropecuária Brasileira, v.19, p.1423-1428, 1984.

GIAROLA, N.F.B.; SILVA, A.P.; IMHOFF, S. Relações entre propriedades físicas e características de solos da Região Sul do Brasil. Revista Brasileira de Ciência do Solo, v.26, p.885-893, 2002.

GOMES, J.B.V.; CURI, N.; MOTTA, P.E.F.; KER, J.C.; MARQUES, J.J.G.S.M.; SCHULZE, D.G. Análise de componentes principais de atributos físicos, químicos e mineralógicos de solos do Bioma Cerrado. Revista Brasileira de Ciências do Solo, v.28, p.137-153, 2004a.

GOMES, J.B.V.; CURI, N.; SCHULZE, D.G.; MARQUES, J.J.G.S.M.; KER, J.C.; MOTTA, P.E.F. Mineralogia, morfologia e análise microscópica de solos do Bioma Cerrado. Revista Brasileira de Ciência do Solo, v.28, p.679-694, 2004 b.

HARIDASAN, M. Nutrient cycling as a function of landscape and biotic characteristics in the Cerrado of Central Brazil. In: MCCLAIN, M.E.; VICTORIA, R.L.E.; RICHEY, J.E. (Ed.). 
Biogeochemistry of the Amazon Basin and its role in a changing world. New York: Oxford University Press, 2001. p.68-83.

KEMPER, W.D.; CHEPIL, W.S. Size distribution of aggregates. In: BLACK, C.A. (Ed.). Methods of soil analysis. Madison: American Society of Agronomy, 1965. v.1, 770p. (American Society of Agronomy. Agronomy, 9).

LIMA, J.M.; ANDERSON, S.J. Aggregation and aggregate size effects on extractable iron and aluminum in two Hapludoxs. Soil Science Society of America Journal, v.61, p.965-970, 1997.

MARQUES, J.D.; LIBARDI, P.L.; JONG VAN LIER, Q. Relação entre horizontes pedológicos e propriedades hidráulicas em dois Latossolos. Revista Brasileira de Ciência do Solo, v.26, p.567-577, 2002.

MOTTA, P.E.F. da; CARVALHO FILHO, A. de; KER, J.C.; PEREIRA, N.R.; CARVALHO JUNIOR, W.; BLANCANEAUX, P. Relações solo-superfície geomórfica e evolução da paisagem em uma área do Planalto Central Brasileiro. Pesquisa Agropecuária Brasileira, v.37, p.869-878, 2002.

MOTULSKY, H.; CHRISTOPOULOS, A. Fitting models to biological data using linear and nonlinear regression: a practical guide to curve fitting. New York: Oxford University, 2003. 351p.

PEDROTTI, A.; FERREIRA, M.M.; CURI, N.; SILVA, M.L.N.; LIMA, J.M.; CARVALHO, R. Relação entre atributos físicos, mineralogia da fração argila e formas de alumínio no solo. Revista Brasileira de Ciência do Solo, v.27, p.1-9, 2003.
ROSSI, M.; MATTOS, I.F. de A.; COELHO, R.M.; DEMARIA, I.C.; FERREIRA, I.C. de M. Parque Estadual de Porto Ferreira, São Paulo: a influência do solo na ocorrência da vegetação natural. O Agronômico, v.57, p.15-18, 2005.

SANTOS, H.G. dos; JACOMINE, P.K.T.; ANJOS, L.H.C. dos; OLIVEIRA, V.A. de; OLIVEIRA, J.B. de; COELHO, M.R.; LUMBRERAS, J.F.; CUNHA, T.J.F. (Ed.). Sistema brasileiro de classificação de solos. Rio de Janeiro: Embrapa Solos, 2006. $306 \mathrm{p}$.

SANTOS, R.D. dos; LEMOS, R.C. de; SANTOS, H.G. dos; KER, J.C.; ANJOS, L.H.C. dos. Manual de descrição e coleta de solo no campo. 5.ed. Viçosa: Sociedade Brasileira de Ciência do Solo, 2005. 92p.

SILVA, E.M. da; AZEVEDO, J.A. de. Período de centrifugação adequado para levantamento da curva de retenção de água em solos do Bioma Cerrado. Planaltina: Embrapa Cerrados, 2001. 41p. (Embrapa Cerrados. Boletim de pesquisa e desenvolvimento, 8).

VAN GENUCHTEN, M.T. A closed-form equation for predicting the hydraulic conductivity of unsaturated soils. Soil Science Society of America Journal, v.44, p.892-898, 1980.

YOUKER, R.E.; MCGUINNESS, J.L. A short method of obtaining mean weight-diameter values of aggregate analyses of soils. Soil Science, v.83, p.291-294, 1956.

Recebido em 20 de abril de 2009 e aprovado em 29 de janeiro de 2010 